\title{
Improving the incremental conductance control method of a solar energy conversion system
}

\author{
J. Kouta ${ }^{1}$, A. El-Ali ${ }^{2}$, N. Moubayed ${ }^{1}$ and R. Outbib ${ }^{2}$ \\ ${ }^{1}$ Department of Electrical Engineering \\ Faculty of Engineering - Lebanese University \\ El-Arez Street, Tripoli (Lebanon) \\ Phone:+00 96138799 56, e-mail: nmoubayed@ieee.org \\ ${ }^{2}$ Laboratory of Sciences in Information and Systems (LSIS) \\ Aix-Marseille III University, Marseille (France) \\ Phone:+00 334910560 17, e-mail: rachid.outbib@lsis.org
}

\begin{abstract}
In the context of renewable energy, this study treats the case of the conversion of solar energy, which is one part of non pollutant energy, to electrical one. Maximizing methods of the generated power is discussed in this paper. Thus, the case of solar panel is studied and a comparison between different strategies of the incremental conductance method in order to maximize the output power is given, analyzed, compared and discussed.
\end{abstract}

\section{Key words}

Renewable energy, solar panel, photovoltaic cell, modelling and control.

\section{Introduction}

In general, the Earth has two global movements that affect the reception of the solar energy to its surface: the rotation that it does once on itself per day and the yearly revolution that it does around the sun. The combination of these movements implies daily changes in the receipt of the solar light to particular places [1]. The reason for which the energizing flux received to soil hardly passes $1000 \mathrm{~W} / \mathrm{m}^{2}$ is that the atmosphere modifies in an important way the direct radiance of the sun by the influence of the following mechanisms [2]:

- absorption of light by the various gases constituent,

- absorption and diffusion by the sprays and the dusts,

- diffusion by their molecules.

In addition, the solar flux received on a surface depends on the:

- orientation and the slant of the surface,

- latitude of the place and its degree of pollution,

- period of the year,

- instant considered in the day,

- nature of the cloudy layers.

The phenomenon named "photovoltaic effect" consists mainly in transforming the solar light in electric energy by means of the semiconductor devices named photovoltaic cells. The solar panel, or photovoltaic generator, is itself constituted of an association of series and parallel of the necessary number of modules to assure the requisite energy [3].

In this paper, we are interested in different method of modelling and control of a solar panel used in a solar production system. More precisely, our goal is to maximize the output power produced by the solar panel. Notice that this problem has attracted the interest of several authors [4],[5],... The paper is organized as follows. Section 2 is devoted to present the system under considerations. Section 3 shows the difference between photovoltaic cell and solar panel. In the fourth section, an analysis of the output power and condition of its maximizing value are given. Simulation results are presented in section 5. Finally, conclusions are given in section 6 .

\section{The process under considerations}

Our system is achieved in the Faculty of Engineering of the Lebanese University in Lebanon. It is constituted of two solar panels, the first stationary and the second mobile. The control of the last took place so that its surface is always perpendicular to the solar rays. The accumulators are placed in order to stock the received solar energy (Figure 1). The using of a microcontroller on the whole system has permitted the interconnection between the two solar panels and the computer in order to archive the values of the produced powers. Another role was to turn the electric motor of the support carrying the mobile panel. In addition, our system contains a weather station. Its role is to manage better the produced power.

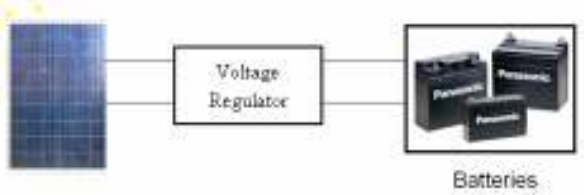

Fig. 1. The solar conversion system 


\section{The solar generator}

\section{A. Modelling of a solar panel}

In the obscurity, a semiconductor presents a high resistance. When it is strongly illuminated, its resistance decreases. If the energy of the photons that constitutes the luminous ray is sufficient, these photons will be able to excite the electrons blocked in the valence layer to jump to the conduction layer. It is the phenomenon of photo conductibility.

The expression of the diode current is described by the following equation:

$$
I_{p}=I_{c c}-I_{d}=I_{c c}-I_{s}\left(\exp \frac{e V_{p}}{k T}-1\right)
$$

with:

- $\mathrm{I}_{\mathrm{p}}$ and $\mathrm{V}_{\mathrm{p}}$ are the current and voltage of this photovoltaic cell,

- $\mathrm{I}_{\mathrm{s}}$ is the saturation current,

- $\mathrm{I}_{\mathrm{CC}}$ and $\mathrm{I}_{\mathrm{d}}$ are the short-circuit and the direct currents,

- $\mathrm{k}$ is the Boltzmann constant (equal to $8,62.10^{-5} \mathrm{eV} /{ }^{\circ} \mathrm{K}$ ),

- $\mathrm{T}$ is the absolute temperature,

- e is the electron charge.

This equation corresponds to a current generator, which models the sunshine, and a diode in parallel, which represents the PN junction. The equivalent circuit of the ideal photovoltaic is given in figure 2 .

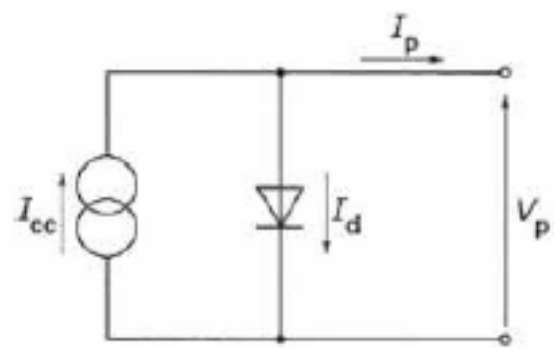

Fig. 2. Equivalent ideal model of photovoltaic cell

To draw the real model of photovoltaic cell, it is necessary to take in account the losses due to the manufacture. Therefore, two resistances should be added to the ideal model, one placed in series and the other in parallel (Figure 3). In fact, the resistance $R_{s}$ represents the losses dues to the contacts and the connections. The parallel resistance $R_{\text {sh }}$ represents the leakage currents in the diode. The characteristic equation becomes then:

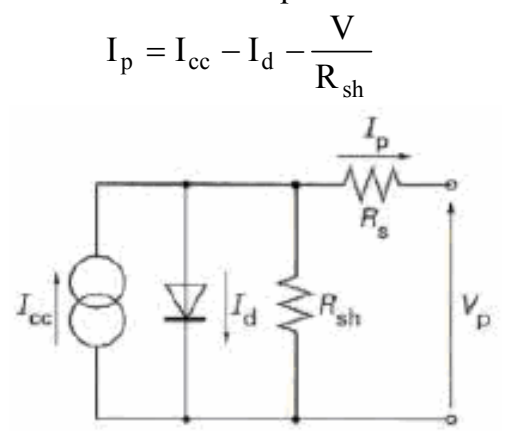

Fig. 3. Equivalent real model of photovoltaic cell

A solar panel is an association in parallel and in series of several cells (Figure 4).

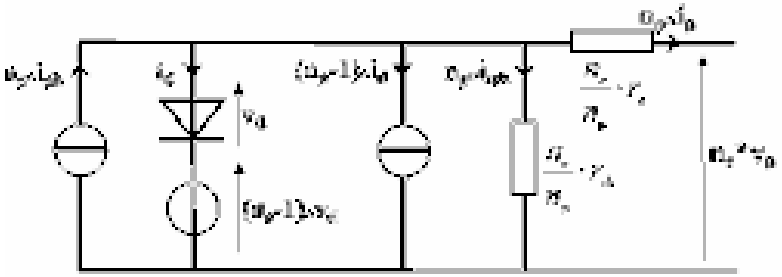

Fig. 4. Model of a real solar panel (ns x np cells)

With: $\mathrm{I}_{\mathrm{ph}}=\mathrm{n}_{\mathrm{p}} \mathrm{i}_{\mathrm{ph}} \quad ; \quad \mathrm{I}_{\mathrm{d}}=\mathrm{n}_{\mathrm{p}} \mathrm{i}_{\mathrm{d}} \quad ; \quad \mathrm{I}_{\mathrm{G}}=\mathrm{n}_{\mathrm{p}} \mathrm{i}_{\mathrm{p}} \quad ;$

$\mathrm{I}_{\mathrm{rsh}}=\mathrm{n}_{\mathrm{p}} \mathrm{i}_{\mathrm{rsh}} \quad ; \quad \mathrm{V}_{\mathrm{d}}=\mathrm{n}_{\mathrm{s}} \mathrm{v}_{\mathrm{d}} ; \mathrm{V}_{\mathrm{G}}=\mathrm{n}_{\mathrm{s}} \mathrm{v}_{\mathrm{p}} ;$

$\mathrm{R}_{\mathrm{sh}}=\frac{\mathrm{n}_{\mathrm{s}}}{\mathrm{n}_{\mathrm{p}}} \mathrm{r}_{\mathrm{sh}} ; \mathrm{R}_{\mathrm{s}}=\frac{\mathrm{n}_{\mathrm{s}}}{\mathrm{n}_{\mathrm{p}}} \mathrm{r}_{\mathrm{s}}$

The characters in capital letter correspond to the panel model, whereas those in lower-case letter are those of an elementary photovoltaic cell. The equivalent model of the solar panel is given in figure 5 .

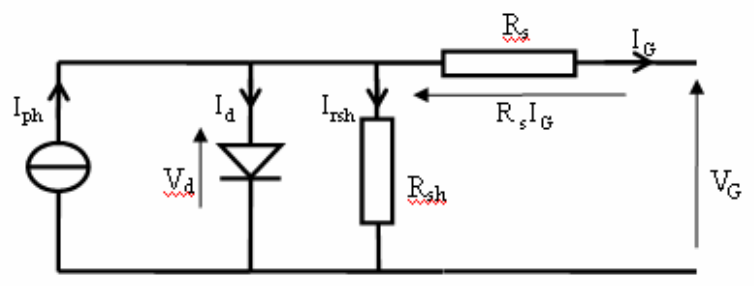

Fig. 5. Equivalent model of the solar panel

The expression of the output current $\mathrm{I}_{\mathrm{G}}$ of the solar panel is [6]:

$$
\begin{aligned}
I_{G} & =P_{1} E_{s}\left[1+P_{2}\left(E_{s}-E_{\text {sref }}\right)+P_{3}\left(T_{j}-T_{j r e f}\right)\right] \\
& -P_{4} T_{j}^{3} \exp \left(-\frac{E_{g}}{k T_{j}}\right)\left[\exp \left(\frac{e\left(V_{G}+R_{s} I_{G}\right)}{K n_{s} T_{j}}\right)-1\right]-\frac{V_{G}}{R_{s h}}
\end{aligned}
$$

where:

- $\mathrm{T}_{\mathrm{j}}$ is the temperature and $\mathrm{T}_{\mathrm{j} \text { ref }}=25^{\circ} \mathrm{C}$ is the temperature reference,

- $\mathrm{E}_{\mathrm{s}}$ is the sunshine and $\mathrm{E}_{\mathrm{s} \text { ref }}=1000 \mathrm{~W} / \mathrm{m}^{2}$ is the sunshine reference,

- $\mathrm{E}_{\mathrm{g}}$ is the gap energy,

- $\mathrm{P}_{1}$ to $\mathrm{P}_{4}, \mathrm{R}_{\mathrm{s}}$ and $\mathrm{R}_{\mathrm{sh}}$ are constant parameters.

Therefore, this model contains two inputs, $\mathrm{E}_{\mathrm{s}}$ and $\mathrm{T}_{\mathrm{j}}$, and two outputs, $\mathrm{I}_{\mathrm{G}}$ and $\mathrm{V}_{\mathrm{G}}$.

\section{B. Output power characteristics}

For any solar panel, the output power is function of the temperature and the sunshine values of the site where the panel is placed. This power can decrease or increase as result of any temperature and/or shining variations.

In Tripoli, the second city of Lebanon, the temperature varied between $0^{\circ} \mathrm{C}$ to $40^{\circ} \mathrm{C}$, and the sunshine changed from zero to $900 \mathrm{~W} / \mathrm{m}^{2}$. For these extremities, the output power versus voltage for different values of temperature is given in figure 6 , and that versus voltage for different values of shining is shown in figure 7 .

In these figures, the output power is not constant. To maximize this power and maintain it constant at high values, it is necessary to define the Maximum Power Point Tracking (MPPT) methods, and apply these methods to controlled dc-dc converters (choppers). 


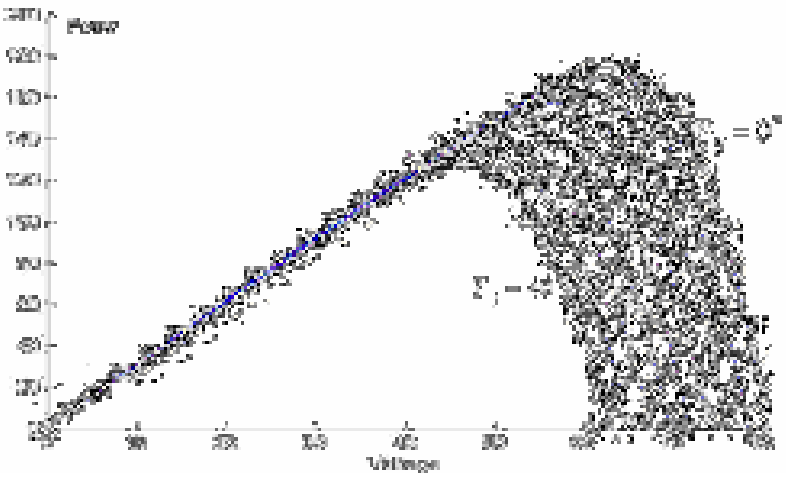

Fig. 6. Output power at different temperature values

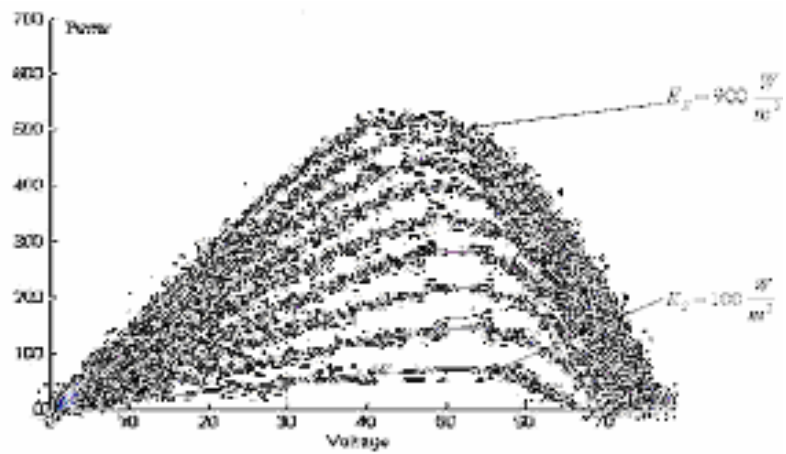

Fig. 7. Output power at different sunshine values

\section{Maximizing the output power}

The output power of a solar panel is a function of the temperature, the sunshine and the position of the panel. It is also function of the product of the voltage by the current. By varying one of these two parameters, voltage or current, the power can be maximized.

Several MPPT methods exist in order to maximize this output power and to fix its value, in steady-state, to its high level. These methods are:

1. Perturb and observe,

2. Incremental Conductance,

3. Parasitic Capacitance,

4. Voltage Based Peak Power Tracking,

5. Current Based peak power Tracking.

In this paper, the incremental conductance method is treated. This method consists in using the slope of the derivative of the current with respect to the voltage in order to reach the maximum power point. To obtain this point, $\mathrm{dI} / \mathrm{dV}$ must be equal to $-\mathrm{I} / \mathrm{V}$ (Figure 8 ). In fact, applying a variation on the voltage toward the biggest or the smallest value, its influence appears on the power value. If the power increases, one continues varying the voltage in the same direction, if not, one continues in the inverse direction. The simplified flow chart of this method is given in figure 9. In addition, by using the power formula $\mathrm{P}=\mathrm{V}$.I, its derivative becomes:

$$
\mathrm{dP}=\mathrm{V} . \mathrm{dI}+\mathrm{I} . \mathrm{dV}
$$

The duty cycle $\left(\alpha_{n}\right)$ of the used chopper (dc-dc converter) is calculated by the following expression:

$$
\alpha_{\mathrm{n}}=\alpha_{\mathrm{n}-1} \pm \Delta \alpha
$$

where $\Delta \alpha$ is the duty cycle step.

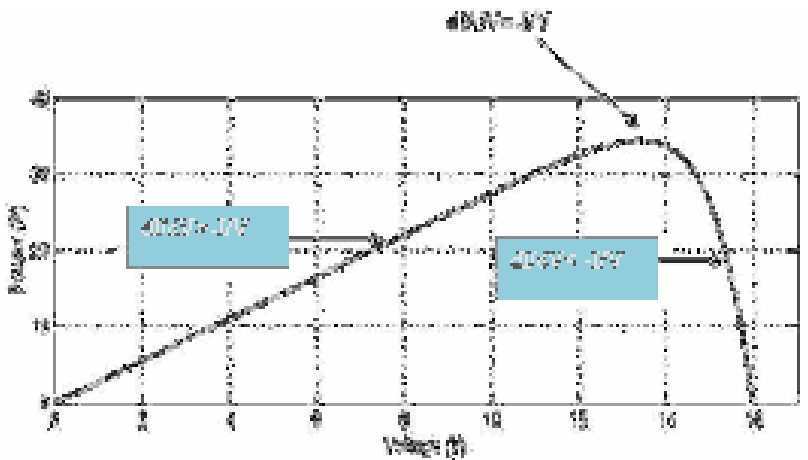

Fig. 8. Output power using the MPPT method, Incremental conductance

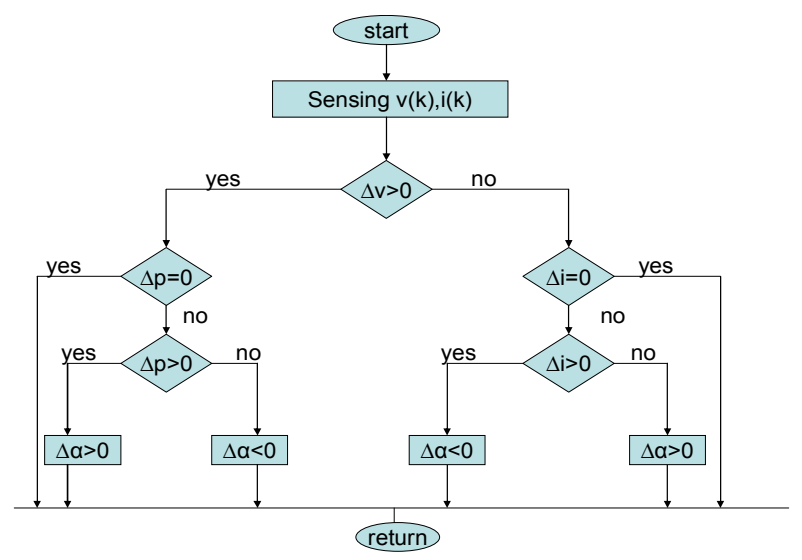

Fig. 9. Incremental conductance method flowchart

\section{Simulation Results}

The studied system is represented in figure 10. The temperature average value is taken equal to $25^{\circ} \mathrm{C}$ with variation of $\pm 15^{\circ} \mathrm{C}$ applied by using the Matlab random function. The sunshine average value is fixed to $600 \mathrm{~W} / \mathrm{m}^{2}$, with variation of $\pm 200 \mathrm{~W} / \mathrm{m}^{2}$ applied by using the Matlab random function.

With the 'Incremental conductance' method, which is already explained in the previous section, the curve of the output power versus time is illustrated in figure 11 . This figure shows that the power value remains approximately constant, with small ripples. Also, the time response is not negligeble.

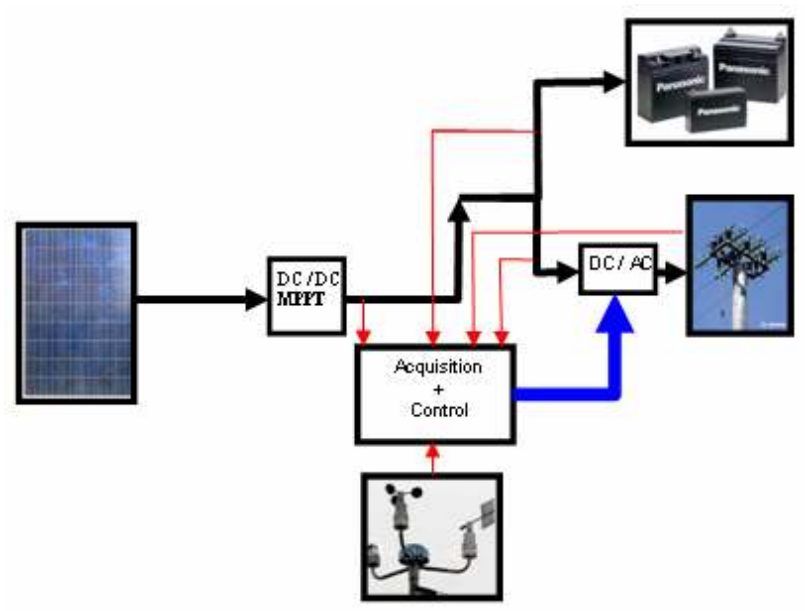

Fig. 10. The studied system 


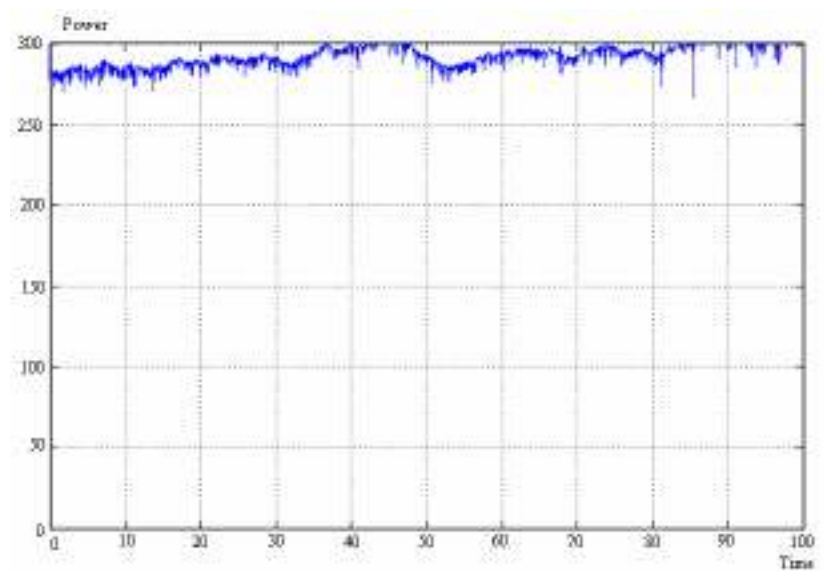

Fig. 11. Power waveform by using the incremental conductance MPPT method

\section{A. Improving the MPPT 'Incremental conductance' method:}

To improve the studied MPPT method, it is proposed to make change on the chopper duty cycle. The new one takes the value of:

$$
\alpha=\frac{\alpha_{\mathrm{n}}+\alpha_{\mathrm{n}-1}}{2}
$$

The obtained power amplitude (Figure 12) takes more important amplitude values than that illustrated in figure 11. The time response is smaller. Therefore, the power is maximized by using this original method. Its disadvantage is the presence of ripples which can be dangerous for charging and discharging the batteries.

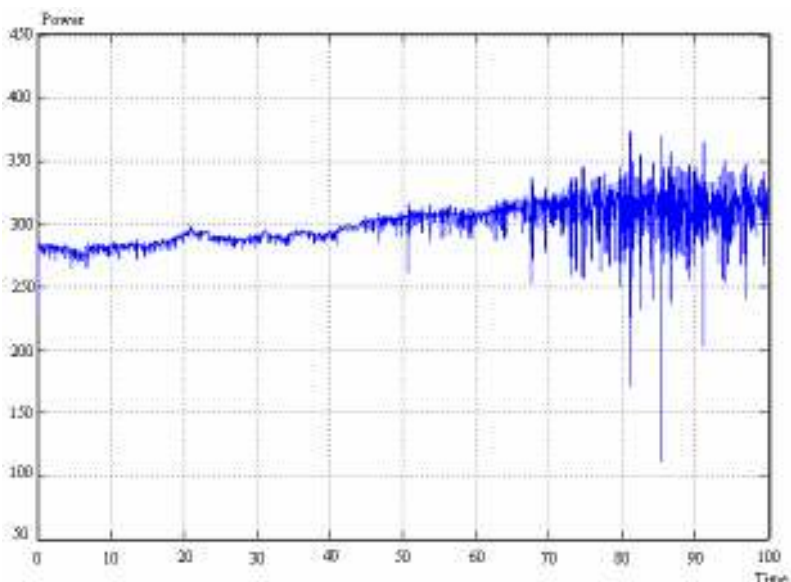

Fig. 12. Power after improving the conductance method

\section{B. The Delta-adaptative method:}

By using the previous methods, the output power waveform contained ripples of different magnitudes. To maintain the output power at its maximum value and to minimize its ripples, the delta-adaptative method can be applied on the MPPT incremental conductance method. The remarkable thing in this method is that the duty cycle $(\alpha)$ is not added by $\Delta \alpha$ or subtracted by $\Delta \alpha$ in a constant way. In other words, $\Delta \alpha$ is not constant. The duty cycle changes with respect to the form of the curve in use. In delta adaptative method, there are two basic algorithms that can be used: the space shuttle and the song algorithm.
By using the space shuttle algorithm, the time response of the output power becomes smaller, and, in steady state, the power ripples are attenuated. The output power waveform is given in figure 13 .

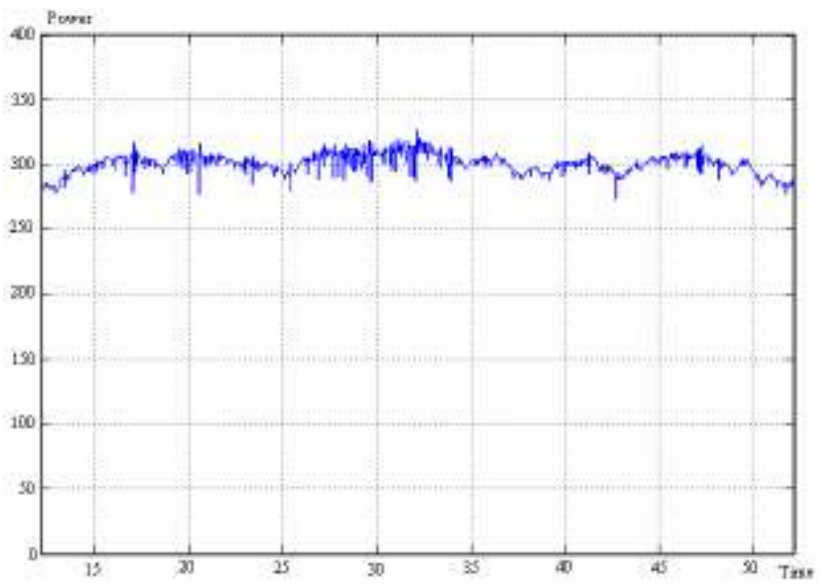

Fig. 13. Power after applying the delta-adaptative method

\section{Conclusion}

The sun is at the origin of the quasi-totality of the sources of energies used by the humanity for its food, domestic and industrial needs. The solar energy is important because it is non pollutant energy. In this paper, after presentation of the studied system, the conversion from solar energy to electrical one is treated. In this case, the functioning of a photocell and a solar panel are analyzed. The 'incremental conductance' method is used to maximize the output power. This method had been improved by using the averaging strategy of the chopper duty cycle. The time responce is reduced, but, ripples of high amplitude appears on the power wave form. To eliminate these ripples, the delta adaptative method was applied on the incremental conductance method. Simulation results prove that the delta adaptative method permits the reduction of the power ripples and gives the maximum value to the power amplitude with a reduced time responce.

\section{References}

[1] A. El Ali, N. Moubayed R. Outbib, "Comparison between solar and wind energy in Lebanon', EPQU'07, 9-11 October 2007, Barcelona - Spain.

[2] M. Zakaria, A. El Ali, N. Moubayed and R. Outbib, "Energie solaire : Bilan annuel, Rendement et Rentabilité', EPE 2006, 12-13 October 2006, IASI - Romania, Volume C, pp. 1571-1578.

[3] L. Protin and S. Astier, "convertisseurs photovoltaïques", Techniques de l'ingénieur Génie Electrique D3 360.

[4] A. \& V. Olgyay, "Solar control and shading devices", Book, Princeton (1976).

[5] V. Salas, E. Olias, A. Barrado \& A. Lazaro, "Review of the maximum power point tracking algorithms for stand-alone photovoltaic systems", Elsevier, 2005.

[6] O. Gergaud, "Modélisation énergétique et optimisation économique d'un système de production éolien et photovoltaïque couplé au réseau et associé à un accumulateur', Thèse de Doctorat de l'ENS de Cachan, 2002 . 